WM'03 Conference, February 23-27, 2003, Tucson, AZ

\title{
REMOVAL OF RETIRED ALKALI METAL TEST SYSTEMS
}

\author{
W. F. Brehm, W. R. Church, and J. W. Biglin \\ Fast Flux Test Facility Engineering, Fluor Hanford \\ P. O. Box 1000, Richland, WA 99352
}

\begin{abstract}
This paper describes the successful effort to remove alkali metals, alkali metal residues, and piping and structures from retired non-radioactive test systems on the Hanford Site. These test systems were used between 1965 and 1982 to support the Fast Flux Test Facility and the Liquid Metal Fast Breeder Reactor Program. A considerable volume of sodium and sodium-potassium alloy (NaK) was successfully recycled to the commercial sector; structural material and electrical material such as wiring was also recycled. Innovative techniques were used to safely remove $\mathrm{NaK}$ and its residues from a test system that could not be gravity-drained. The work was done safely, with no environmental issues or significant schedule delays.
\end{abstract}

\section{INTRODUCTION}

The Nuclear Energy Legacies Sodium Disposition project was established to dismantle and remove retired non-radioactive alkali metal test systems on the Hanford Site. These test systems were used between 1965 and 1982 to support the Fast Flux Test Facility and the Liquid Metal Fast Breeder Reactor Program. A decision was made to dismantle the facilities and recycle the sodium and sodium-potassium alloy (NaK), because there was no further use for the facilities or the alkali metals within the U. S. Department of Energy (DOE) complex.

Sodium and $\mathrm{NaK}$ are both designated hazardous materials. Further, their extreme chemical reactivity with air and moisture requires maintaining an inert cover gas for safe handling and storage. The hazardous materials designation also means that a higher level of monitoring, fire protection, emergency preparedness, and safety documentation must be maintained on buildings where these materials are stored. Dismantling the systems and removing the alkali metals from the Hanford Site will eliminate expenses associated with the increased level of surveillance, as well as make staff available for other work. In addition, removing the retired test systems from the buildings housing them makes space available for other work, and reduces overhead costs by removing the systems and equipment from property-management accounts. 
WM'03 Conference, February 23-27, 2003, Tucson, AZ

\section{SUMMARY}

To date (February 2003) we have dismantled six retired test systems and shipped the sodiumwetted piping and selected components to an off site treatment center; removed sodium residue from six sodium tanks and one NaK piping system; and shipped approximately $180,000 \mathrm{~kg}$ of sodium and $425 \mathrm{~kg}$ of NaK off site to be recycled. Approximately 500 meters of small-diameter sodium wetted pipe, and several other components have been shipped off site to a treatment center. We have done all this while maintaining a good safety and environmental compliance record. The project has been very successful in large part because of the extremely effective teamwork among management, engineering, operations, safety, and environmental regulatory organizations. More detailed discussion of tasks and remaining work are provided below.

\section{ENVIRONMENTAL AND OTHER DOCUMENTATION AND ANALYSES}

Before field work was begun, an Environmental Assessment was completed (1), and a Categorical Exclusion for a substantial part of the work was obtained. In addition, analyses were conducted to ensure that we were not disturbing local plant, animal, and bird species, and that historical sites were not being disturbed. These reviews did not reveal anything that required us to change our plans.

\section{BULK SODIUM REMOVAL}

Each of the retired systems had a tank where the sodium was drained after the test operations were completed. The tank capacity ranged from 115 liters to 190,000 liters. The tanks were heated to approximately $150^{\circ} \mathrm{C}$ to melt the sodium; the sodium was then pressure and/or vacuum transferred to receiving vessels. Sodium from smaller tanks was transferred into U. S. Department of Transportation (DOT)-rated drums; sodium from the two larger tanks was transferred into rail cars. The drums and rail cars containing solid sodium were shipped off site.

We decided to conduct all sodium melt-and-drain operations in Hanford's 300 Area, rather than at some of the outer, more remote locations. Hanford's 300 Area is relatively close to highly populated areas and the Columbia River. Therefore, this decision meant that a safety analysis had to be performed on the effects of transporting the tanks, and also that some of the tanks had to be prepared for transport. It was necessary to provide escorts and institute a "rolling road closure" for moving the tanks on the approximately $20 \mathrm{~km}$ of highway open to the public, between the Hanford Wye barricade and the 300 Area. Two small ( $<1500$ liters capacity) tanks from the Hanford T Plant and a 19,000-liter tank (1720-DR tank) from the 105-DR Area were shipped to the 300 Area in this fashion. 
WM'03 Conference, February 23-27, 2003, Tucson, AZ

For the smaller tanks, we verified that the existing heaters on the tanks were operable. The heaters were connected to temporary control systems and temporary transfer piping systems; the piping was routed to DOT-rated 208-liter (55 gallon) drums. Stainless steel tubing (1.7 or $2.3 \mathrm{~mm}$ wall thickness, $25 \mathrm{~mm}$ outside diameter), small stainless steel all-welded, bellows seal valves, and compression fittings were used for constructing the transfer lines. Valves were either operated manually, or when appropriate for worker safety, operated by air or nitrogen pressure. The final assembled transfer pipe was pressure tested at $1 \frac{1 / 2}{2}$ times the maximum anticipated pressure, and then purged with nitrogen gas to $<0.1 \%$ oxygen. The transfer line was preheated before sodium was admitted to the transfer systems. A "dip tube" was inserted through a purged compression fitting to the bottom of the tank after the sodium was melted; the fitting was then tightened and the tube connected to the transfer piping. Pressures of up to $0.1 \mathrm{MPa}$ were used as motive force for the transfer. Overfilling the drums was prevented by placing the drums on a scale and limiting the amount of sodium transferred into a drum to approximately $180 \mathrm{~kg}$. After the sodium was transferred to the drums and cooled down, an argon atmosphere was established, and the drums were then sealed shut. The drums were then transported to the various receiving organizations.

The sodium in the two larger tanks was sold to an off site company who required that the sodium be loaded into rail cars. The 1720-DR tank mentioned above was placed next to a set of railroad tracks; the other tank was placed in a building serviced by the tracks.

Heaters and insulation were added to the 1720-DR tank, and again a temporary heating and control system was constructed from existing equipment. The transfer piping and dip tube arrangement was similar to that described previously. For this tank, a combination of pressure on the tank and vacuum in the rail car was used for transfer. The volume of sodium in the 1720-DR tank did not fill much of the rail car capacity, so no liquid level determination was required. A sonic probe was used to determine the liquid level in the 1720-DR tank. The sonic probe measured the time it took for a sound wave to travel from the probe to the sodium surface and return.

The largest tank (3718-M tank) was located in a separate building below grade and adjacent to the high bay where the rail car would be positioned. The transfer route was a combination of existing piping that was part of the retired test system, connected to $25 \mathrm{~mm}$ stainless steel tubing, which routed the sodium to the rail car. Figure 1 shows a schematic of the transfer piping. An additional dip tube was inserted into the tank to drain the bottom $100 \mathrm{~mm}$ or so of sodium: the existing fill and drain piping was deliberately terminated above the bottom of the tank to always leave a sodium heel in the tank during test-system operation. 
WM'03 Conference, February 23-27, 2003, Tucson, AZ

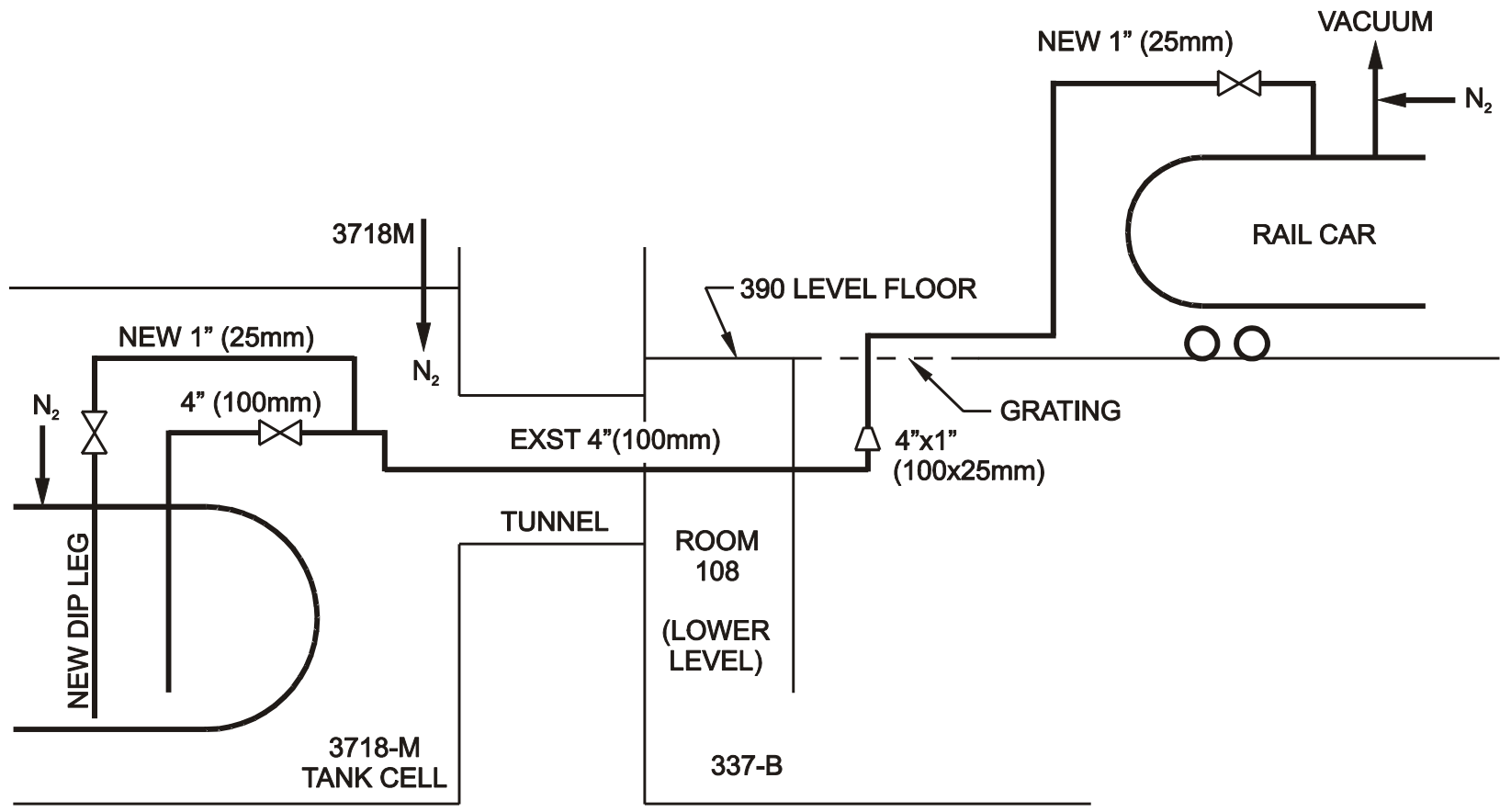

Figure 1. 3718-M Sodium Transfer Line Schematic

The existing tank heaters and 25-year-old control system proved operable, although considerable effort was required to restart and maintain the control system. We maintained the tank temperature during downtime for changing out the rail cars, rather than risk stopping and starting the heating elements and control system. The heating and control system for the (approximately) 30 meters of temporary transfer piping was similar to that used for the other tanks.

Transfer was again made by a combination of pressure on the tank and vacuum in the rail car. Three rail cars were required to accept the entire sodium inventory from the two tanks (approximately 180,000 liters). A flow rate of approximately 22 liters/minute was achieved during the transfer. Liquid level in the tank was again measured with the sonic probe; in the rail car the sodium level was at first measured by determining when two wires immersed in sodium were bridged by sodium and short-circuited. However, this approach was not particularly effective and was replaced by temperature measurement with a thermocouple. (The liquid sodium is warmer than the partial vacuum above it.) It took about 48 hours of round-the-clock operation to fill one rail car, with another day or two required to set the rail car in place, connect the transfer lines, pressure check the system, establish the vacuum on the rail car, and heat the transfer lines. The rail cars were not heated during the transfer. Two teams, each working 12-hour shifts, provided continuous coverage during sodium flow 
WM'03 Conference, February 23-27, 2003, Tucson, AZ

Because of the large volume of sodium to be transferred, and the proximity of the Columbia River and also hundreds of workers in the 300 Area, additional formal safety analyses were performed for transfers of sodium from the two large tanks. A more formal readiness review process was conducted for the transfer of the largest tank. For other transfers, a less formal but rigorous and thorough review was performed before starting work. Particularly useful were "what-if" sessions where responses/reactions to upset and unusual conditions were discussed and formulated. Responses to emergencies such as large sodium spills, but also more mundane events, such as the lights going out, were evaluated.

\section{BULK NaK REMOVAL}

The NaK to be removed was in a piping system (loop) with no drain tank or provisions for draining. Piping size was mostly $50 \mathrm{~mm}$, with smaller diameter tubes, about $19 \mathrm{~mm}$, in the tube bundle of a NaK to oil heat exchanger. The oil had been drained from the system and recycled several years before removing the $\mathrm{NaK}$ was begun. $\mathrm{NaK}$ is liquid at room temperature. It was therefore necessary to cool several sections of the loop below the $\mathrm{NaK}$ freezing point of $-12^{\circ} \mathrm{C}$, to connect the transfer lines safely. The $\mathrm{NaK}$ was then transferred to vessels rated by DOT for hazardous flammable liquids and shipped off site. Additional care and controls were established for this operation because of NaK's extreme reactivity. The system was left under argon cover gas until the NaK residues were removed.

Because the loop had been under static argon cover gas for more than 15 years, we were concerned that air had leaked into the system. Should this have been the case, then potassium superoxide, a powerful and shock sensitive oxidizing agent, could have formed. Potassium superoxide also will react with potassium metal to form potassium oxide and liberate large quantities of heat. A gas sample showed the presence of some nitrogen in the cover gas, indicating that a small amount of air had possibly leaked in. We estimated the potential amount of potassium superoxide that could be present was small, and decided that the loop could be drained safely if we were extremely careful about admitting air into the loop.

We ascertained that using multiple drain points would provide the best chance for a safe and effective drain. Several of the drain points required drain lines to be attached to the piping system at locations where the pipes were full of $\mathrm{NaK}$. To safely attach drain piping to the loop, the following steps were performed:

A short length, about $100 \mathrm{~mm}$, of $13 \mathrm{~mm}$ diameter tubing, with an end prepared to accept a valve and compression fitting, was welded onto the tube.

The $\mathrm{NaK}$ in the adjacent area was frozen by applying liquid nitrogen, captured in spongelike material fastened to the outer diameter of the pipe, to the pipe until the temperature had decreased to well below the freezing point of $\mathrm{NaK}$.

A hole was drilled in the pipe with the drill bit passing through the $13 \mathrm{~mm}$ diameter tubing. A nitrogen purge was provided to the adjacent area while this process was underway. 
WM'03 Conference, February 23-27, 2003, Tucson, AZ

The bellows-sealed, all-welded valve was threaded on the end of the piping and the valve closed. This sealed the system.

The rest of the transfer piping was attached, purged with nitrogen and transferred to the DOT-approved receiving vessels, and transfer initiated using gas pressure.

Part of the transfer process involved removing $\mathrm{NaK}$ from an annulus around a larger vessel. The annulus had been partially drained during the operation described above. Here, entry into the cover gas space would provide a viable connection to the $\mathrm{NaK}$ in the annulus. The following sequence was used:

The NaK level in the annulus was determined by eddy-current inspection.

A short length of tubing, prepared to accept a valve, was welded to the outside of the annulus wall as described above.

A ball valve was fastened to the end of the tube. After the area, including the inside of the tubing, was purged with nitrogen, a hole was drilled in the annulus wall through the hole in the ball valve, maintaining a nitrogen purge.

The drill bit was withdrawn and small-diameter $(<10 \mathrm{~mm})$ dip tubes were inserted through the ball valve and into the annulus.

The dip tubes were connected to transfer piping leading to the receiving vessel.

Two iterations of the above process were required to get a dip tube to the bottom of the annulus.

Again, the weight of the receiver vessel was used to determine when a vessel was filled to capacity. The receiver vessels in this case were not 208-liter drums, but welded vessels with dip tubes and valves approved for transporting flammable liquids. These tanks are essentially identical to the large propane tanks sold in home center retail stores.

We were able to mockup most steps of the operation before actual performance. A full-sized mockup of the annulus and vessel was built to practice inserting the dip tubes. Various designs for devices to retain liquid nitrogen could be used on the NaK loop itself, in the actual work locations. This work helped us determine how long it took to freeze the NaK and how long work could safely be performed on the system before the area warmed up and re-melted the $\mathrm{NaK}$. Because of the concerted effort in planning, procedure development, and mockup testing, and the skill and care of the workers, the $425 \mathrm{~kg}$ of $\mathrm{NaK}$ was transferred uneventfully.

Since this NaK drain was a first-of-a-kind evolution, except for the drain of about 8 liters of $\mathrm{NaK}$ done early in the program using similar techniques, a more formalized review process, including "what-if" sessions, was used to ensure readiness to perform this work. 
WM'03 Conference, February 23-27, 2003, Tucson, AZ

\section{SODIUM-WETTED PIPING}

A process and cost analysis showed that the small-diameter piping associated with the systems $125 \mathrm{~mm}$ and smaller - should be cut into manageable lengths, packed in DOT-rated drums, and shipped to an off site waste treatment center as hazardous waste. The piping contained sodium residues; in numerous instances, however, the piping was full of solid sodium. These pipes were cut safely and efficiently with mechanical wheeled cutters and portable band saws. More aggressive cutting equipment, such as plasma-arc cutters, was considered but not used.

The sequence followed when removing piping was as follows:

Remove all electrical power to the affected system.

Remove insulation, trace heat, and instrumentation (e.g., thermocouples).

Make initial cut into the system using a hand-powered cutter, with a nitrogen purge. This step was done to avoid any sparks or heat that could ignite residual hydrogen in the piping (the source of the hydrogen would be from water vapor in air that had leaked into the system during years of storage).

Subsequent cuts could be performed with power bandsaws. An inert gas purge was not required after the initial cut. We watched very closely for sparks or burning sodium; there were very few. While sodium carbonate powder was always available to smother any small "fireflies," it was rarely needed. Figure 2 shows a cut being made on a section of pipe.

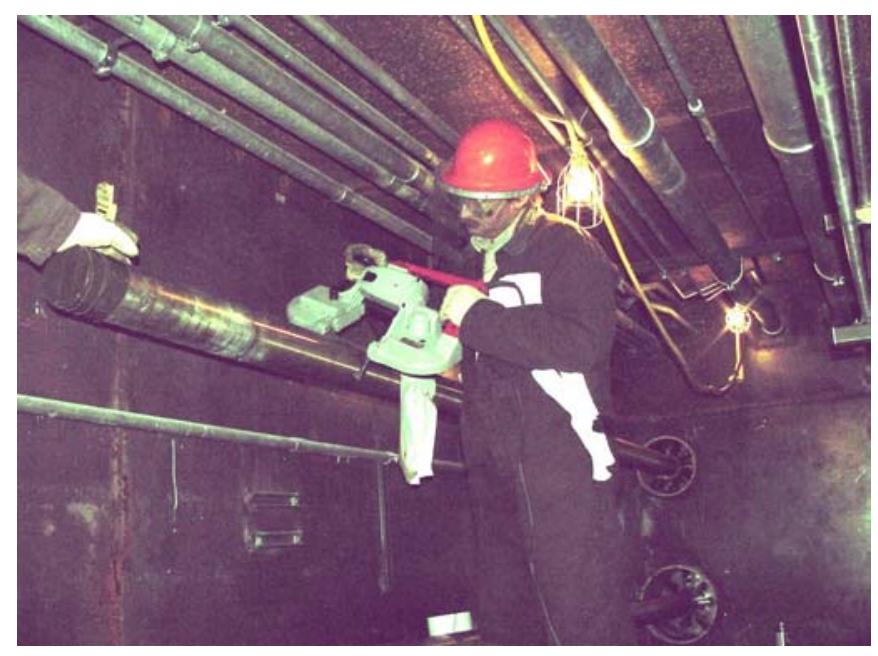

Figure 2. A Craftsman Uses a Portable Bandsaw to Cut Sodium-Wetted Pipe 
WM'03 Conference, February 23-27, 2003, Tucson, AZ

Cut sections of piping were taped over on the ends, or capped with plastic caps, and loaded into the 208-liter drums for shipment to an off site waste treatment center. Since solid sodium reacts very slowly with ambient temperature air, it was not necessary to provide an inert gas purge to the piping sections, seal-weld them closed, or provide an inert gas cover on the drums.

\section{RESIDUE REMOVAL FROM TANKS}

This task required a small, portable cleaning station to be built. The system cleaned the tank by using water vapor obtained by passing nitrogen through a moisture column and into the tank. The reaction products are concentrated aqueous sodium hydroxide, which is periodically removed from the tank and sent to users on the Hanford Site, and hydrogen gas, which is vented off. Typical system operating parameters are as follows:

Flow rate of moist nitrogen about $2.8 \mathrm{~m}^{3} / \mathrm{hr}(1.6 \mathrm{scfm})$.

Moisture column temperature about $22^{\circ} \mathrm{C}$, producing about $1 \frac{1}{2} \%$ water vapor in nitrogen.

The system is equipped with monitors for measuring oxygen and hydrogen in the flowing gas stream. The oxygen is purged from the system being cleaned before bringing the moisture column into the gas flow circuit. The moisture column is simply a vertical cylinder filled with Raschig rings and distilled/demineralized water. The water is periodically replenished. Two hydrogen meters have been used; one measuring as high as $10 \%$ hydrogen in nitrogen; the other, measuring in the range $10-500 \mathrm{ppm}$. The hydrogen meters are periodically calibrated against standard gas mixtures (which, in turn, have been calibrated by sampling and analysis against standards traceable to the National Institute for Science and Technology). Typical hydrogen levels attained during operation are $0.3 \%$ to $3 \%$.

A relief system, comprising a $50 \mathrm{~mm}$ diameter check valve set to open at $70 \mathrm{kPa}$ venting through $50 \mathrm{~mm}$ diameter piping into drums, has been installed to confine reaction product in case of unexpected rapid sodium-water reactions and resulting pressure pulses. Because of the low throughput and low hydrogen levels attained, the system can run unattended once conditions have stabilized. Data such as temperature and hydrogen level is collected and can be processed in a personal computer incorporated into the data-collection system.

After the sodium has been converted to sodium hydroxide, the tanks are rinsed with potable water a minimum of three times per regulatory requirements. To date, six tanks, the largest having a capacity of 19,000 liters, have been cleaned by this process. Figure 3 shows the cleaning system set up to clean the 19,000 liter tank, which contained over $100 \mathrm{~kg}$ of residual sodium. 
WM'03 Conference, February 23-27, 2003, Tucson, AZ

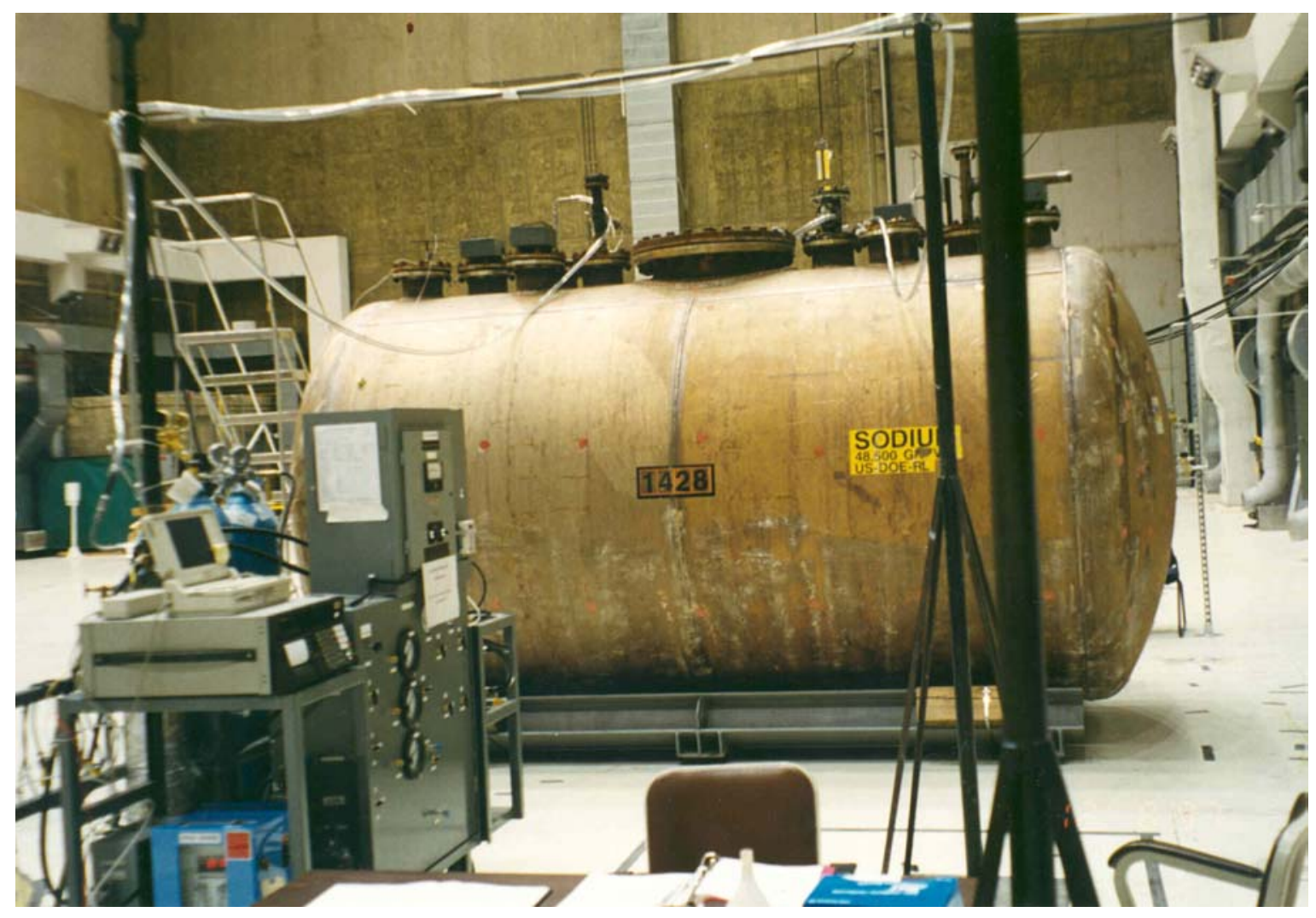

Figure 3. Cleaning Station for Reacting Residual Sodium

We sent out a request for proposal to hire an outside contractor to clean sodium residue from our two remaining large tanks (each with a volume of more than 150,000 liters, which is more than our current cleaning station can handle). Removing the residue from these two tanks will complete the removal of non-radioactive alkali metal associated with the Legacies project.

\section{RESIDUE REMOVAL FROM NaK PIPING}

It was deemed unsafe to attempt to cut up the $\mathrm{NaK}$ loop with its residues, so $\mathrm{NaK}$ residues were removed from the system ( $50 \mathrm{~mm}$ diameter and smaller, plus a "surge tank") via the water vapornitrogen process. Several entrance points into the loop were established, using the existing drain hardware installed during the bulk $\mathrm{NaK}$ drain, to ensure that the water vapor injection and following rinse reached all parts of the loop.

Because the bulk NaK had been drained more than two years before the NaK residue was removed, we decided to blow down the piping system again to drain any $\mathrm{NaK}$ that had settled in pools in low spots. Small vessels were fabricated and connected to the original drain points. We collected a small volume of $\mathrm{NaK}$, less than $1 \mathrm{~kg}$. 
WM'03 Conference, February 23-27, 2003, Tucson, AZ

It was necessary to cut into the loop in several places to attach the piping from the cleaning station, and the check valve/piping system (see above) to contain surges in pressure. Because we knew there was $\mathrm{NaK}$ residual in the piping, all workers did the work wearing full protective clothing and face shields. Nitrogen purges were set up to eliminate or minimize air leaking into the system. The entire operation, including transporting the removed sections of piping to a drum for disposal, was choreographed and rehearsed before actual performance. The cutting and welding sequence to configure the loop for cleaning occurred uneventfully. Figure 4 shows workers performing the welding.

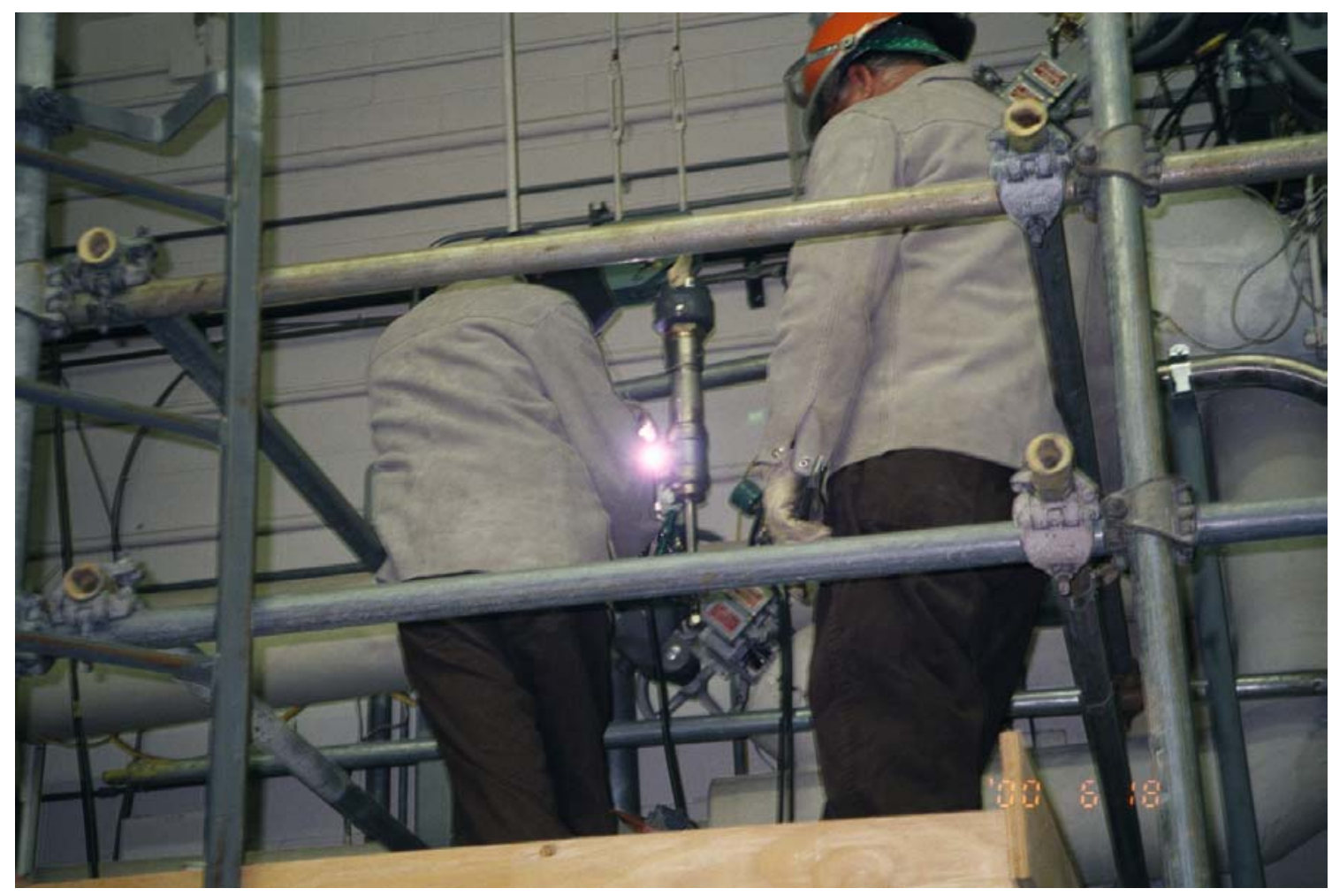

Figure 4. Welding NaK Loop Piping

The cleaning station was set up in a different room from the loop, so that all control operations except actual hookup and movement of the connecting piping could be performed in an adjacent room away from the loop, and separated by a concrete floor. Water injection was secured and the nitrogen purge maintained during times when the connecting piping was moved from one water injection point to another. The $\mathrm{NaK}$ reaction process was almost anticlimactic less than $1 \mathrm{~kg}$ of $\mathrm{NaK}$ was converted to sodium/potassium hydroxide and the hydrogen level did not exceed $4 \%$. This small amount of residual $\mathrm{NaK}$ is attributable to the excellent drain operation and the second smaller drain process mentioned above.

Again, a rigorous readiness evaluation was performed before preparing the system for cleaning and beginning the cleaning process. 
WM'03 Conference, February 23-27, 2003, Tucson, AZ

\section{INSPECTION OF COMPOSITE REACTOR COMPONENT TEST ACTIVITY (CRCTA) VESSEL}

The CRCTA vessel is one of the two remaining large tanks to have the sodium residue removed. Information provided to us at the start of the project showed that as much as 10,000 liters of sodium was left inside the vessel. This amount caused concern for two reasons: the uncertainty of how the residual sodium would be distributed inside the vessel and the potential need for a difficult, complex, and expensive melt-and transfer operation to remove most of the residue. (Unlike the rest of the tanks we drained, this vessel has no provisions for heating except for some immersion heaters hanging down into the tank; these heaters must be surrounded by sodium to work effectively.) A review of tank drawings and test programs raised doubt about the accuracy of the 10,000-liter figure.

Therefore, the tank internals were inspected. Air had to be prevented from entering the tank, to avoid reaction of the potentially finely divided sodium frost. A small video camera was mounted on a 13-mm diameter steel rod to maintain its configuration and to make insertion easier. A vented glove bag, 1-m high and equipped with gloves at its lower end at the entrance port (bolted flange) into the tank, was constructed and fitted around the entrance port and the camera/support rod. After the bag was purged with nitrogen to less than $0.1 \%$ oxygen, a slow nitrogen purge flow was established through the vessel. The entrance port was then opened and the camera lowered slowly, via a combination of crane and chainfall, to the bottom of the vessel. Nitrogen flow and pressure were adjusted to maintain a positive pressure of approximately $50 \mathrm{~mm}$ of water during the time that the camera was inside the vessel. It was possible to rotate the camera through almost a full circle by maneuvering the support rod through the bag, enabling a panoramic view of the tank internals to be maintained. It took approximately two hours to traverse the tank from top to bottom.

The video showed that the inside of the tank was surprisingly clean, with little sodium residue clinging to the walls and internal structure. A pool of solid sodium, approximately $100 \mathrm{~mm}$ deep, was found at the bottom of the tank. Using that information and estimating the amount of sodium trapped on the thermal baffle plates near the top of the tank, we revised the estimate of residual sodium in the tank to approximately 1360 liters. The amount and location of the residue will allow us to react the sodium residue without attempting to melt and transfer it out of the tank. 
WM'03 Conference, February 23-27, 2003, Tucson, AZ

\section{STRUCTURAL MATERIALS AND ELECTRICAL COMPONENTS}

Much material, such as structural steel, diamond-checker steel plate, copper wire, copper bus bars, and thermocouple wire could be salvaged from the systems' supporting structures and electrical/control systems; this material was sent to recycle. Other materials containing asbestos, lead-based paint, and other hazardous components were disposed of according to applicable regulatory requirements, without any particular difficulty.

\section{SAFETY CONSIDERATIONS}

An operation such as the one discussed here involves dealing with many hazardous conditions and situations besides the obvious ones of alkali metal reactivity. Some are listed below:

The work place atmosphere had to be carefully monitored for oxygen depletion when inert gas purges and blankets were used.

Most of the systems, particularly the older ones, contained asbestos in insulation and electrical wiring, as well as refractory materials. Abatement programs using trained and certified workers, isolated work spaces with proper ventilation, and proper disposal of asbestos containing materials were necessary.

As confirmed with portable material testers, most of the paint on the structural materials contained lead. We found it expedient to treat almost all painted materials as containing lead-bearing paint. Taking this approach meant that cutting torches could not be used to disassemble structural materials, and control had to be maintained over chips and metal fines produced during cutting operations.

Some of the work was conducted out-of-doors in a desert environment; hazards such as bird waste, insects, and snakes had to be recognized, and controlled.

Extra care was taken to ensure that all electrical power had been removed from systems before starting to dismantle them. Fortunately, a good drawing file was available on most of the systems, thus making this effort easier.

When we dug into the ground, special attention had to be given to locating energized underground power lines to avoid digging them up. Careful scans with groundpenetrating radar minimized this hazard.

Even though piping systems had been constructed to drain under gravity or slight gas pressure, we found that many of the systems, even piping up to 100 -mm diameter, did not drain well. This situation can cause problems when it is assumed that a section of pipe has only a sodium film, when it in fact it is full of solid sodium. This situation contributed to the decision to cut up small sodium piping and send it to a treatment center rather than attempt to remove the residues in place.

We involved the safety and environmental compliance organizations early in the planning, and were able to avoid significant delays, re-planning, and rework, and minimized environmental compliance problems. 
WM'03 Conference, February 23-27, 2003, Tucson, AZ

\section{CONCLUSION}

The effort to remove the non-radioactive bulk alkali metal and associated piping systems from the Hanford Site has been successful. Work of this nature requires careful planning and a disciplined approach to ensure success. The excellent teamwork among work groups, different contractors, and the DOE contributed significantly to the success. The operation has been conducted safely, under budget, and on schedule.

\section{ACKNOWLEDGMENTS}

The authors would like to acknowledge the excellent support provided by the engineering staff, technician staff, craft workers, financial staff, management and the DOE during the progress of this work. The teamwork shown among the various groups and organizations contributed significantly to our success. The work was sponsored by the United States DOE under contract DE-AC06-96RL13200.

\section{REFERENCE}

1. DOE/EA-0987, Environmental Assessment, Disposition of Alkali Metal Test Loops, Hanford Site, Richland, Washington, May 1995, U. S. Department of Energy, Washington, DC.

2. HNF-14082, Removal of Retired Alkali Metal Test Systems, W. F. Brehm, W. R. Church, J. W. Biglin, Fluor Hanford, January 2003. 